\title{
New Technique for Picking Up Large Colorectal Tumors during Endoscopic Submucosal Dissection
}

\author{
Hideyuki Chiba ${ }^{a}$ Ken Ohata ${ }^{a}$ Yusuke Sekino ${ }^{a}$ Takafumi Ito ${ }^{a}$ Yosuke Tsuji ${ }^{a}$ \\ Tomohiko Ohya $^{a}$ Masahiko Inamori ${ }^{b}$ Atsushi Nakajimab Nobuyuki Matsuhashi ${ }^{\mathrm{a}}$

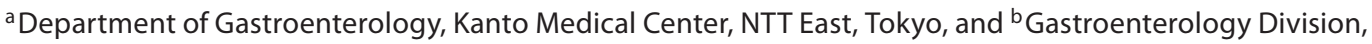 \\ Yokohama City University School of Medicine, Yokohama, Japan
}

Dear Sir,

Endoscopic submucosal dissection (ESD) enables us to resect large superficial tumors en bloc. In cases with very large tumors resected en bloc, however, retrieval of the resected specimen is often difficult. Here we present a novel method for retrieval of large resected tumors.

Fig. 1. A Endoscopic view of an 80-mm rectal tumor. B The upper overtube is the modified tube. The lower one is the original tube. C, D The specimen was successfully picked up en bloc using the modified overtube.
We treated a 45-year-old woman with a laterally spreading rectal tumor about $80 \mathrm{~mm}$ in size (fig. 1A). This tumor was resected en bloc by ESD. In our hospital, an overtube (flexible overtube, Sumitomo Bakelite, Tokyo, Japan) is often used to pick up large specimens. This time, the specimen was too large to retrieve with the
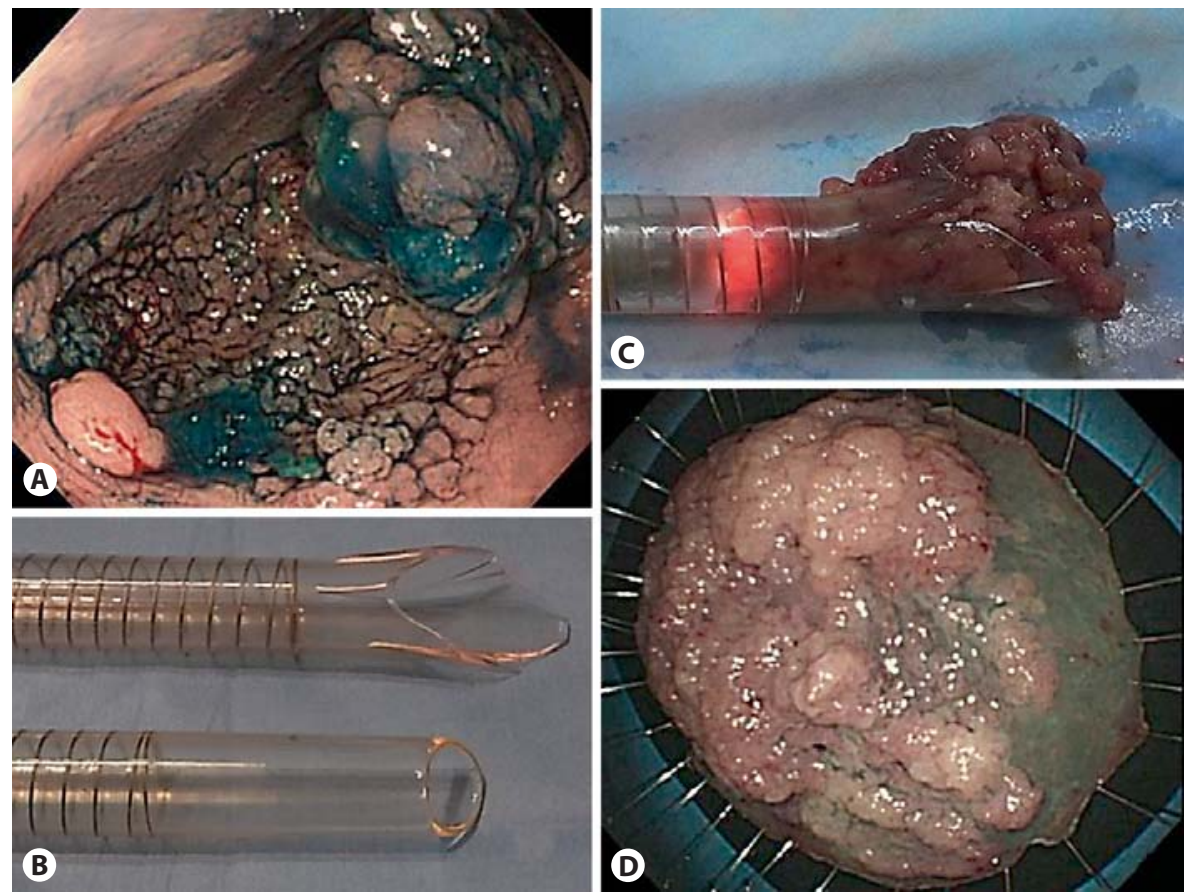

aid of a conventional overtube. Thus, we modified the overtube as follows: we cut the distal end of the tube in an oblique fashion and slit the distal tip of the tube to increase the holding capacity of the overtube (fig. 1B). This modification enabled us to pick up the tumor en bloc without injuring the tissue (fig. 1C, D).

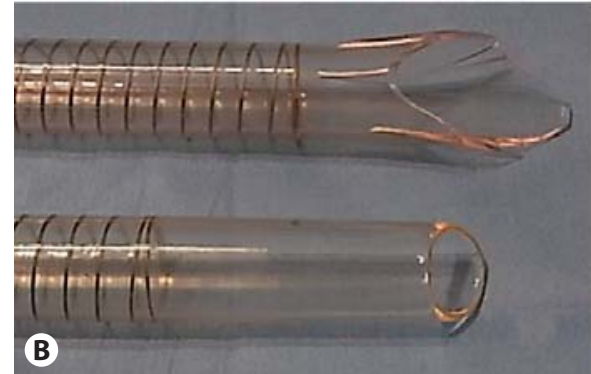

\section{KARGER}

Fax +4161306 1234 E-Mail karger@karger.ch www.karger.com 
Recently, ESD has been used as endoscopic treatment for the resection of superficial colorectal tumors regardless of the tumor size. Compared with conventional endoscopic mucosal resection, en bloc ESD allows a more accurate pathological diagnosis and may be superior in preventing residual disease and local recurrence $[1,2]$. The resected specimen should therefore be carefully retrieved, and a reliable method for picking up tumors without damaging the tissue is need- ed. However, the use of available devices including clamping forceps, nets, or overtubes often results in fragmentation of large tumor specimens during retrieval. Using the modified overtube described above, however, very large tumors or highly elevated lesions can be removed without damaging tumor tissues. In the future, we hope to further improve this overtube to produce a more secure and reliable recovery tool.

\section{References}

1 Fujishiro M, Yahagi N, Kakushima N, Kodashima S, Muraki Y, Ono S, Yamamichi N, Tateishi A, Oka M, Ogura K, Kawabe T, Ichinose M, Omata M: Outcomes of endoscopic submucosal dissection for colorectal epithelial neoplasms in 200 consecutive cases. Clin Gastroenterol Hepatol 2007;5:678-683.

2 Tanaka S, Oka S, Chayama K: Colorectal endoscopic submucosal dissection: present status and future perspective, including its differentiation from endoscopic mucosal resection. J Gastroenterol 2008;43:641-651. 